\title{
Perceived Body Size and Weight Control Practices of Adolescents in Rural and Urban Communities in South Western Nigeria
}

\author{
Oladapo B. Oyewole ${ }^{1}$, Oluyemisi F. Folasire ${ }^{2}$, Idowu A. Ayede ${ }^{3}$, Babatunde O. Adedokun ${ }^{1} \&$ David M. Dairo ${ }^{1}$ \\ ${ }^{1}$ Department of Epidemiology and Medical statistics, Faculty of Public Health, University of Ibadan, Ibadan. \\ Nigeria \\ ${ }^{2}$ Department of Human Nutrition, College of Medicine, University of Ibadan \& Family Medicine Dept., \\ University College Hospital, Ibadan, Nigeria \\ ${ }^{3}$ Department of Paediatrics, College of Medicine, University of Ibadan, Ibadan, Nigeria \\ Correspondence: Oluyemisi F. Folasire, Dept. of Human Nutrition, University of Ibadan, Ibadan, Nigeria, West \\ Africa. Tel:234-803-400-2041. E-mail: yemisifolasire2011@ gmail.com
}

Received: September 16, 2017 Accepted: October 11, $2017 \quad$ Online Published: January 12, 2017

doi:10.5539/jfr.v7n1p86

URL: https://doi.org/10.5539/jfr.v7n1p86

\begin{abstract}
Introduction and Objectives: Body size perception has been described as the image of our own shape created in our imagination. Body image perception determines the adolescent engagement in weight control activities, such as bulimia and anorexia. A misperception of body size may lead the adolescent into engagement in weight control activities that may be injurious to adolescent's health. This study assessed the perceived body size and weight control practices among adolescents in different settings.

Methodology: A cross-sectional, multistage cluster sampling method was used to recruit 913 adolescents in Ibadan North Local Government, Ibadan, Nigeria who were interviewed using a semi-structured, self-administered questionnaire. Anthropometric measurements were taken; perceived body size were determine by Stunkard Figure Rating Scale Silhouette. Analysis was done using the Chi-square statistic and $p<0.05$ level of significance.

Results: Over four-fifths $(87.4 \%)$ of the adolescents wrongly perceived their actual body size. Body size overestimation was reported by both females and males. About $11.3 \%$ respondents recorded making an effort to reduce weight whereas, $12.7 \%$ recorded they were also involved in gaining weight. Over twice as large urban respondents $(14.7 \%)$ engaged in weight reduction habits contrast to rural $(6.8 \%)$. Majority of females with normal weight perceived themselves overweight $\left(\lambda^{2}=50.06, \mathrm{p}=0.000\right)$. More males were involved in weight gain practise $\left(\lambda^{2}=6.94, \mathrm{p}=0.031\right)$.

Conclusion: The increased frequency of body weight misperceived within rural/urban adolescents and the reported influence and motivation of weight control behaviours, makes adolescent education on assessment of their weight and BMI imperative in adolescent health care services.
\end{abstract}

Keywords: body image perception, obesity, weight control practices, adolescents

\section{Introduction}

Globally, overweight and obesity combined has risen in prevalence by $27.5 \%$ for adults and $47.1 \%$ for children between 1980 and 2013(Marie et al., 2013). Obesity has become an epidemic disease in industrialised and increasing in undustrialised countries (Trishnee \& Rajesh, 2014)(Maruf, Akinpelu, \& Nwankwo, 2012). Obese infants remain more prone to develop into obese adolescents, and obese adolescents remain more prone to develop into obese adults (Goodman, \& Hinden, 2000).

As stated by World Health Organisation (WHO), overweight and obesity are number five in the series of prominent exposure for universal mortality, approximately 2.8 million adults die every year as a consequence of being overweight or obese (Knight \& Illingworth, 2009). Also, 44\% of the diabetes problem, 23\% of the ischaemic heart disease problem and between $7 \%$ and $41 \%$ of certain cancer problems are inferable to overweight and obesity (Wong, 2010).

Lately, there was an increased prevalence in adolescent's Body Mass Index mean level of about $0.2 \mathrm{~kg}$ per year in 
some Europe and Asia countries (Mahshid, Noori, \& Anwar, 2005). Unmodified estimate of being underweight differed from $12.6 \%$ (Egypt) to $31.9 \%$ (Djibouti), as being overweight varied between $8.7 \%$ (Ghana) to $31.4 \%$ (Egypt). Obesity estimates varied from $0.6 \%$ (Benin) to 9.3\% (Egypt) (Manyanga, El-sayed, \& Doku, 2014).

In Nigeria, early data on adolescents' obesity and overweight in the middle and later part of the last $20^{\text {th }}$ century suggested a low prevalence, but recent reports from studies indicated an increasing prevalence (Brener, Eaton, \& Lowry, 2006)( Okeke \& Ibeh, 2006). In a population-based study of adolescents in Nigeria, obesity was present in $21 \%$ of males and $28 \%$ of females. Obesity tends to be associated with non-communicable diseases (Iliyasu, I. Abubakar, S. Abubakar, Lawan, \& Gajida 2013). Its impact has become notable due to its important impact on both physical and mental health and the intermediate risk factor to other non-communicable diseases (Yan, Harris, \& Wang, 2009). In Nigeria, compared with other African countries, the risk of overweight has increased amidst children 10 to 18 years of age (13\%) compared to those in 5 to 9 years of age groups (9.4\%), with the frrequency estimates of overweight and obesity advancing amidst urban Nigerian children and adolescents and of equivalent significant to the pervasiveness of undernutrition (National Population Commission[NPC], 2006).

Perceived size has been described to be an image of our own shape created in our imagination (Burns \& Tijihuis, 2001). Accurate perception of body size is a significant influence on adolescent's healthful habits and weight reduction (Maruf, Akinpelu, \& Nwankwo, 2012). Inaccurate image of one's actual body size and having a particular desire for an ideal body size that is larger than WHO's approved, might diminish a person's desire to reduce weight and keep up a healthful weight (Knight \& Illingworth, 2009). Hence, knowing the body size perceptions held by individual has significant health associations (Knight \& Illingworth, 2009). Instigating people to observe their size accurately may be an efficient system for regulating excessive weight challenges. Individuals with excessive weight who observe themselves as overweight or obese are more probably to commit in weight reduction activities, while individuals with an excessive bodyweight who do not perceive themselves overweight will not commit themselves in weight loss behaviours (Wong, 2010)(Brener, Eaton, \& Lowry, 2004).

In Nigeria, studies have mentioned the understanding of size status among non-rural residents (Okeke \& Ibeh, 2006)(Olaoye \& Oyetunde, 2012)( Maruf \& Akinpelu, 2014)( Iliyasu, et al.,2013). Even so, published studies on size status perception of Nigerians in rural areas are rare. Such studies are required to analyse the Body Mass Index-related outcome, particularly within the rural adolescent population since there is limited information in rural population worldwide.

Overweight or obese adolescents and young adults ought to have a precise and proper self-evaluation and healthful weight control behaviours in order to effectively control the epidemic (Yan, Harris, \& Wang, 2009). This study, therefore, assessed the perception of body size as well as weight control practices among rural and urban adolescents.

\section{Materials and Methods}

\subsection{Study Design}

A cross-sectional study was conducted among 913 adolescents in Ibadan, South-western Nigeria.

\subsection{Study Site and Participants}

The research was conducted at districts different from one another in Ibadan North Local Government Area. Ibadan North Local Government contains 12 districts. These districts were divided into homogenous strata of urban and rural communities using the Census Bureau definition of urban and rural (NPC, 2006). Ibadan North Local Government Area is positioned on an angular distance $8^{\circ} 5^{\prime}$ East of the Greenwich meridian and angular distance $7^{\circ} 23^{\prime}$ North of the great circle. On the report of the 2006 population enumeration (provision result); it has a population size of 306,763 . The male residents are given as 153,039 while female residents as 153,756 (NPC, 2006). The Ibadan North LGA is populated mainly by Yoruba dialect people and comprises city and hovel communities. The occupants are majorly marketers, teaches, public servants and scholars. The Local Government also accommodates some academic establishments such as the premier university (University College Ibadan), University College Hospital (College of Medicine), The Polytechnic Ibadan and many private and public secondary and primary schools.

\subsection{Sampling Technique}

A cross-sectional, multistage cluster sampling system was used to enrol participants into the study. The Nigerian Population Commission's enumeration blocks planning in Ibadan North Local Government formed the six districts. Simple random sampling technique (toss of a die) was used to select three from the total districts. Probability proportional to size method was used to select for each section the number of participants to be recruited. An opening, a noticeable indicator such as commercial enterprise, sanctuaries, minaret or bus terminal 
was elected in each district. Using the spin of a bottle, the route to follow from the indicators were determined. Each successive dwelling was explored till the required number for that section was completed. Assistant investigators (residents of Ibadan North Local Government) assisted in the finding of noticeable indicator separating the six districts. They were further effective in the earlier community based contact with the natives. Inclusion criteria; children within the ages of 10 and 19 years old, with self-identify principal care giver in the randomly selected wards were recruited. Respondents with illness fourteen days prior to the study were ruled out.

\subsection{Data Collection Procedures}

Using a self-administered, semi-structured questionnaire, information on socio-demographic data and weight control practice were collected. The anthropometric measurements including weight, height as determined as per Centers for Disease Control and Prevention (CDC) Growth Chart: (BMI $<5$ th percentile: Underweight; BMI $\geq$ 5th and $<85$ th percentile: Normal weight; BMI $\geq 85$ th and $<$ 95th percentile: Overweight; and BMI $\geq 95$ th percentile: Obese) (World Health Organization Multicentre Growth Reference Study Group, 2006). Stunkard Figure Rating Scale Silhouette was used to ascertain perceived body size of participants (see appendix 2). The Stunkard scale rises gradually in measurements between underweight (a value of 1) to very overweight (a value of 9) and it contains nine silhouette figures (Elizabeth et al., 2009) Based on other findings (Elizabeth et al., 2009) (Bhuiyan, Gustat, Srinivasan \& Berenson, 2003), we categorised these figures into underweight (figures 1 and 2), normal weight (figures 3 and 4), overweight (figures 5 through 7), and obese (figures 8 and 9). All evaluations were conducted twice, and mean values documented. BMI was computed as weight $(\mathrm{kg}) /$ height $\left(\mathrm{m}^{2}\right)$ to one decimal place. The questionnaire was preliminarily tested in a similar group of adolescents at a different Local Government, with significant internal consistency, Cronbach's alpha of 0.75 .

\subsection{Data Analysis}

Every statistical analyses was performed with STATA 13. The main outcomes for this research were: being obese, overweight, or underweight as stated by the recommendations set out by the WHO for adolescent (World Health Organization Multicentre Growth Reference Study Group, 2006)(Onis, Onyango, Borghi, Siyam, \& Nishida, 2007). Categorical variables were analysed with the chi-square test. The degree of statistical significance was determined at $P$ value $<0.05$.

Quality control: Study protocol was preliminarily tested, among adolescents in a different Local Government Ward. The research assitants were trained and retrained midway into data management and collation periods. Every questionnaire was validated instantly to reduce lost data. Charged voltaic cells were obtainable for the Omron body composition scale and detached at the recess daily.

\subsection{Ethical Clearance}

The study protocol was approved by the Institutional Review Committee of the Oyo State Research Ethical Review Committee Ministry of Health Secretariat Ibadan Ethical Board.

\section{Results}

\subsection{Actual Size Based on BMI}

In terms of locality, 183 males and 212 females were from rural area while 230 males and 288 females were from urban area respectively (see appendix 1). The mean age of the respondents was $16.0 \pm 1.5$ years. Based on total body mass index (BMI), 3.7\% were underweight (1.8\% in male versus $6.6 \%$ in female); $91.9 \%$ were overweight $(100.0 \%$ in male versus $91.2 \%$ in female; and about $11.8 \%$ were of normal weight $(7.0 \%$ in male versus $15.0 \%$ in female). $\left(\lambda^{2}=33.04, \mathrm{p}=0.000\right)$, Table 1 .

\subsection{Body Size Perception}

Over four-fifths $(87.4 \%)$ of the respondents reviewed wrongly assessed their actual size. Overestimation of body size was documented by $80.0 \%$ of the females and $93.5 \%$ of males Figure 1. Majority (71.4\%) of respondents that were actually underweight perceived they were overweight /obese, while $86.7 \%$ that were normal weight perceived they are overweight /obese and more than $90 \%$ of the respondents that are overweight perceived themselves to be overweight /obese., Table 1. The females had a significant difference in actual BMI and perceived body size, $\left(\lambda^{2}=50.06, \mathrm{p}=0.000\right)$, 
Table 1. Relationship Between Body Mass Index and Respondent's Perceived Body Size (N=913).

\begin{tabular}{lllllll}
\hline \multicolumn{7}{c}{ Perceived Body Size } \\
\hline & BMI & Underweight & Normal weight & Overweight/Obese & $\lambda^{2}$ & P-value \\
\hline \multirow{3}{*}{ All (n=913) } & Underweight & $10(3.7)$ & $68(24.9)$ & $195(71.4)$ & & \\
& Normal weight & $9(1.6)$ & $71(11.8)$ & $523(86.7)$ & 33.04 & $0.000^{*}$ \\
& Overweight & $0(0.0)$ & $3(8.1)$ & $34(91.9)$ & & \\
\hline \multirow{4}{*}{ Male (n=413) } & Underweight & $3(1.8)$ & $25(15.0)$ & $139(83.2)$ & & \\
& Normal weight & $4(1.7)$ & $17(7.0)$ & $222(91.4)$ & 7.35 & 0.119 \\
& Overweight & $0(0.0)$ & $0(0.0)$ & $3(100.0)$ & & \\
\hline \multirow{3}{*}{ Female (n=500) } & Underweight & $7(6.6)$ & $43(40.6)$ & $56(52.8)$ & & \\
& Normal weight & $5(1.4)$ & $54(15.0)$ & $301(83.6)$ & 50.06 & $0.000^{*}$ \\
& Overweight & $0(0.0)$ & $3(8.8)$ & $31(91.2)$ & & \\
\hline
\end{tabular}

*Statistically significant $\mathrm{p}<0.05$.

Table 2. Weight Control Practices of Respondents by Actual Body Mass Index and Gender (N=913)

\begin{tabular}{lllllll}
\hline & Categories & No weight control & Weight Lost & Weight Gain & $\lambda^{2}$ & P-value \\
\hline \multirow{2}{*}{ Actual BMI (N=913) } & Underweight & $212(77.7)$ & $10(3.7)$ & $51(18.7)$ & & \\
& Normal weight & $456(75.6)$ & $85(14.1)$ & $62(10.3)$ & 101.69 & $0.000^{*}$ \\
& Overweight & $13(35.1)$ & $22(59.5)$ & $2(5.4)$ & & \\
\hline \multirow{2}{*}{ Sex (N=913) } & Male & $291(70.5)$ & $63(15.3)$ & $59(14.3)$ & 6.94 & $0.031^{*}$ \\
& Female & $390(78.0)$ & $54(10.8)$ & $56(11.2)$ & & \\
\hline
\end{tabular}

*Statistically significant $\mathrm{p}<0.05$.

Table 3. Body Weight Control Practices and Respondent's Perceived Body Size Categories ( $\mathrm{N}=913)$

\begin{tabular}{lllllll}
\hline & Categories & No weight control & Weight Lost & Weight Gain & $\lambda^{\mathbf{2}}$ & P-value \\
\hline Perceived Body size (N=913) & Underweight & $11(57.9)$ & $3(15.8)$ & $5(26.3)$ & & \\
& Normal weight & $110(77.5)$ & $14(9.9)$ & $18(12.7)$ & 5.02 & 0.285 \\
& Overweight & $560(74.5)$ & $100(13.3)$ & $92(12.2)$ & & \\
\hline \multirow{2}{*}{ Rural (n=395) } & Underweight & $3(37.5)$ & $2(25.0)$ & $3(37.5)$ & & \\
& Normal weight & $43(82.7)$ & $6(11.5)$ & $3(5.8)$ & 11.58 & $0.021^{*}$ \\
& Overweight & $260(77.6)$ & $24(7.2)$ & $51(15.2)$ & & \\
\hline Urban (n=518) & Underweight & $8(72.7)$ & $1(9.1)$ & $2(18.2)$ & & \multirow{2}{*}{$0.044^{*}$} \\
& Normal weight & $67(74.4)$ & $8(8.9)$ & $15(16.7)$ & 7.94 & \\
\hline
\end{tabular}

*Statistically significant $\mathrm{p}<0.05$.

\section{Proportion of wrongly perceived body size among respondents}

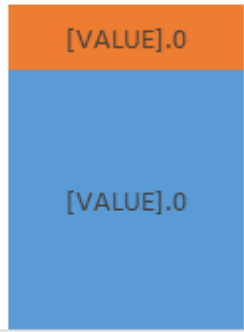

Females

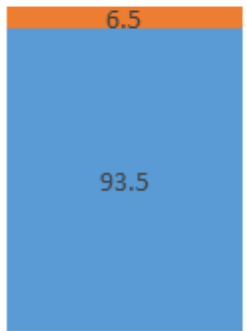

Males

Wrongly perceived a Rightly perceived

Figure 1. Proportion of wrongly perceived body size among respondents 
Proportion of weight control practices among respondents

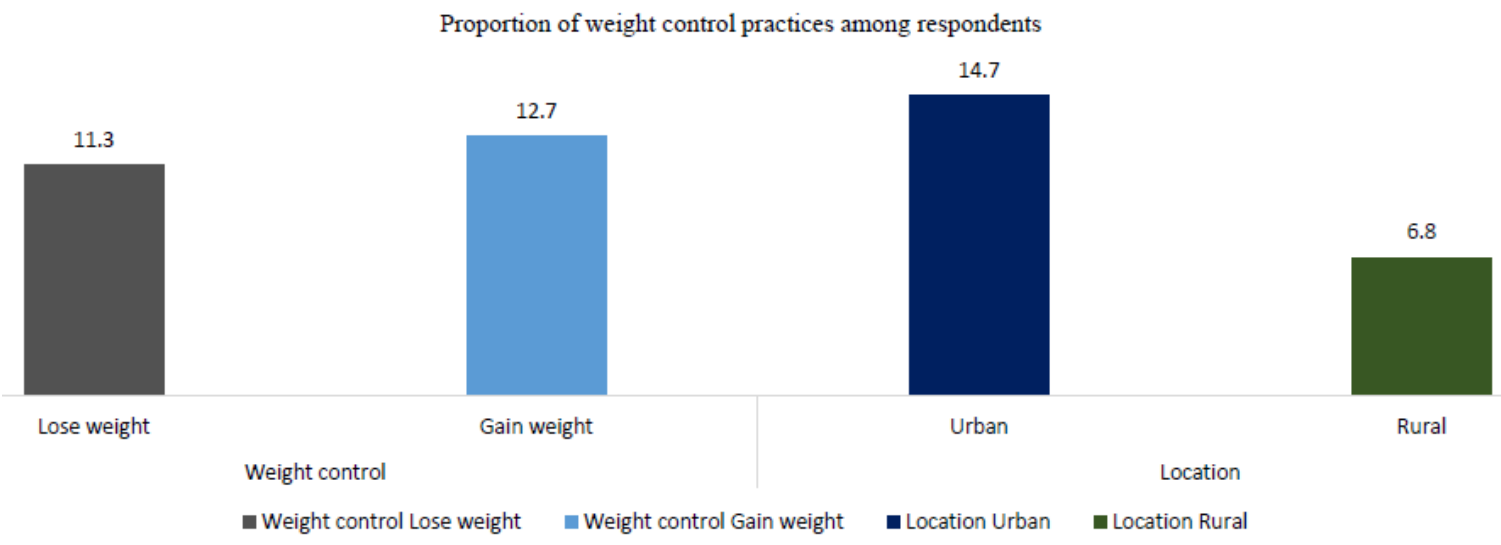

Figure 2. Proportion of weight control practices among respondents

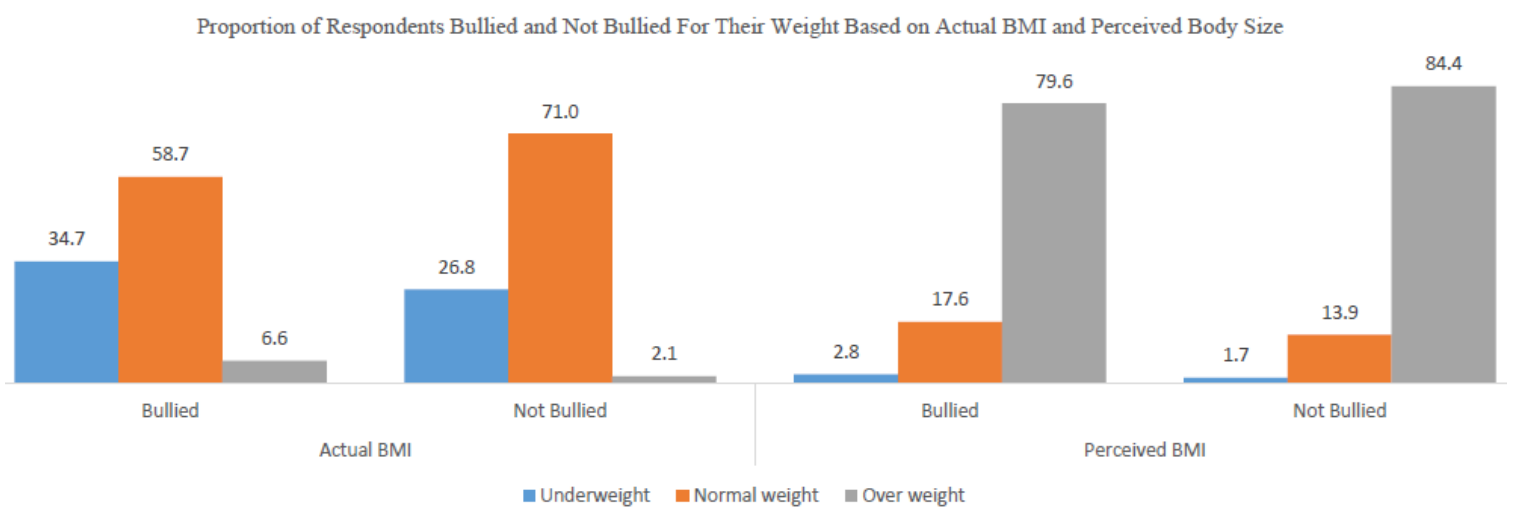

Figure 3. Proportion of Respondents Bullied Based on Actual BMI and Perceived Body Size

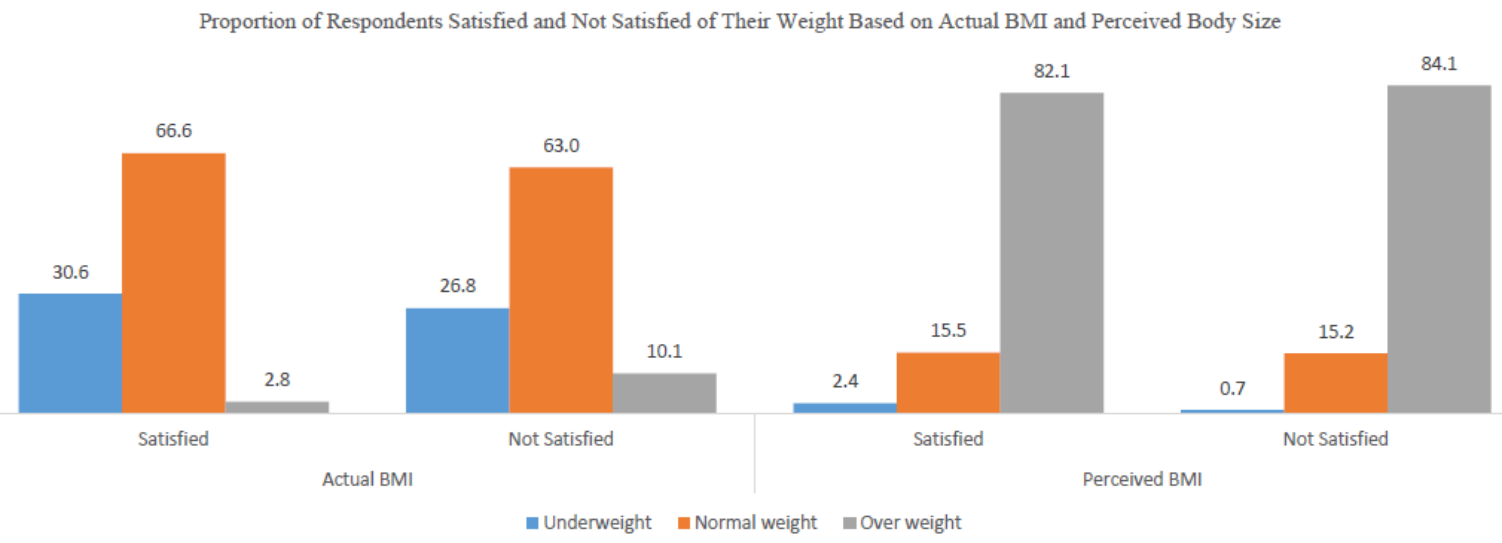

Figure 4. Proportion of respondents' satisfied and not satisfied with size based on actual BMI and perceived Body Size 


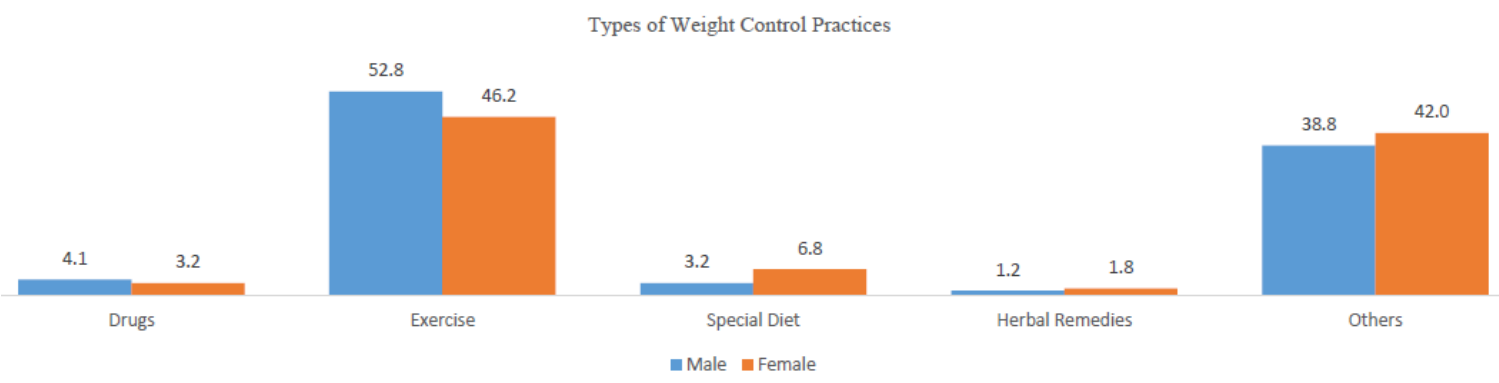

Figure 5. Types of Weight Control Practices

\subsection{Weight Control Practices}

Table 2 shows that male (14.3\%) were more involved in weight gain than female $(11.2 \%)\left(\lambda^{2}=6.94, \mathrm{p}=0.031\right)$. Respondents that documented their intentions to lose weight were $11.3 \%$ so also, $12.7 \%$ reported that they were engaged in weight gain activities. The prevalence of urban respondents (14.7\%) involved in weight loss practices were two times double compared to the rural respondents (6.8\%) Figure 2.

Table 3 shows a significant association linking body size perception and weight reduction habits, such that $7.2 \%$ rural $\left(\lambda^{2}=11.58, \mathrm{p}=0.021\right)$ and $18.2 \%$ urban $\left(\lambda^{2}=7.94, \mathrm{p}=0.044\right)$ of those involved in weight loss behaviour perceived they were overweight.

\section{Body size reaction of respondents:}

Satisfaction and bullying were the two most cited size reaction concerns among respondents. Based on actual BMI, 58.7\% of normal weight respondents were bullied for their size while $6.6 \%$ overweight were bullied $\left(\lambda^{2}\right.$ $=20.17, \mathrm{p}=0.000$ ). Meanwhile based on perceived size, $79.6 \%$ of overweight respondent were bullied and $17.6 \%$ of normal weight $\left(\lambda^{2}=3.53 \mathrm{p}=0.171\right)$, Figure 3 . About $66.6 \%$ normal weight respondents were satisfied with their size while, $2.8 \%$ were not based on actual BMI $\left(\lambda^{2}=16.46 \mathrm{p}=0.000\right)$. Also, $82.1 \%$ of overweight respondents were satisfied while $15.5 \%$ normal weight were satisfied based on perceived BMI $\left(\lambda^{2}=1.62 p=0.446\right)$ Figure 4.

\subsection{Types of Weight Loss Practices}

Four separate dieting habits were evaluated to decide weight reduction practices. The most generally reported habits by all the respondents were exercise (male: $52.8 \%$; females:46. $2 \%$ ), while herbal remedies (male:1.2\%; females: $1.8 \%)$ was of the lowest frequency. $\left(\lambda^{2}=9.49, \mathrm{p}=0.050\right)$ Figure 5 .

\section{Discussion}

The aim of this research was to study body size perception and weight reduction habits amidst rural/urban adolescents, meanwhile the result shows that majority of respondents had the wrong perception of their body size. Males compared to females overestimated their size, while more urban respondents took part in weight loss practices compared to rural respondents. Bullying was a major size concern in overweight female than male respondents.

This study reported a poor correlation of actual weight status with size perception and also, a significant gender differences in body size perception. Overestimated body size and engaging in weight gain activities were higher among males than females whose body size perception tends to be inaccurate when compared to BMI.

Substantially, a high proportion of respondent's size was inaccurately perceived compared to their BMI values similar to Maruf, Akinpelu, \& Nwankwo, (2012) but in contrast to Olaoye, \& Oyetunde, (2012), where 46.0\% had the wrong perception. This present study shows that majority of the respondents that had well balanced BMI perceived they were overweight or obese; most were also females. This maybe based on the self-ideal body size perception by females reported Maruf et al., (2012) which this study was not set out to assess. Maruf et al., (2012) reported that discrepancy in perceived body size reflect body dissatisfaction and can be a factor for weight loss activities. Also, in this current study, overestimation of body weight was more frequently reported among males than females. This may be a perception that needs further insight as was similarly reported by a recent study in Nairobi, where males have a strong preference for the larger body sizes (Ettarh, Van de Vijver, Oti, \& Kyobutungi, 2013). However, this finding is contrary to the previous report by Strauss, (2000) who reported more female body weight exaggeration than male.

Though this current study is in agreement with Boutelle, Neumark-Sztainer, Story, Resnick (2002), who reported 
a higher proportion of urban respondents compared with rural respondents that attempted weight reduction. According to Boutelle et al., (2002), Urban respondents with excessive body weight were more likely to lose weight than those in the rural communities.

In this current study, body size perception has a significant association with weight control rather than actual BMI. This was similarly reported by Goodman, \& Hinden, (2000); Manyanga et al., (2014); Maruf, Akinpelu, \& Nwankwo, (2012); Knight, \& Illingworth (2009). Considering, the geographical settings, according to Maruf, Akinpelu, \& Nwankwo, (2012), dieting and engaging in weight control methods are more likely to be frequent among non-rural female adolescents than rural female adolescents. However, contrary to the previous report, in this present research, both urban and rural respondents were equally involved in weight control methods. It is important to state there is a dearth of published literature at the time of this write up to compare this current study.

Despite the fact that the objective of this research was not to evaluate the relationship between respective documented understanding of weight reduction and healthy habits as well as physical activity level, however, in agreement with Goodman, \& Hinden, (2000) and Manyanga, El-Sayed, \& Doku, (2004) findings, adolescents who declared attempting to reduce weight were comparatively sedentary and did not satify the international recommendations of at least 2.5 hours of average-strength aerobic physical activity throughout the week or do at least 75 minutes of energetic-strength aerobic physical activity throughout the week or an equivalent combination of average and energetic-intensity activity (Goodman, \& Hinden,2000; Mayanga et al., 2014). It is obvious from the current study that adolescent do not know the appropriate approaches for weight loss.

\section{Conclusion \& Recommendations}

The conclusion from this research comfirms that body size was poorly perceived among both urban and rural Nigerian adolescents. In view of the overall misconception on body size among rural/urban adolescents and the association between body size perception and motivation to engage in weight control behaviours. This research, accordingly, proposes that adolescents need be enlightened on the significance of observing their weight and BMI regularly in order to avert variation from healthful weight. Enlightenment on the health implication of being underweight, overweight or obese as well as risk-free and efficient long-term weight control solution should be advocated. Enlightenment can be accomplished by course of instruction, fitness familiarity campaign, disserminating therapeutic flyer, issueing related reviews and via the news (social media networks, telecasting, radio communication and newsprint).

\section{Limitation and Suggestion for Further Research}

Due to size reduction stigmatization among adolescents in south west Nigeria, this study observed poor adherence among male population hence, foresight must be applied when extrapolating findings and also, the study overlooked association between size reduction and socioeconomic status (SES) of the respondents. Prospective reviews need to research both ideas as they predetermines body size and weight control practices.

\section{Acknowledgements}

Authors appreciate every respondent who took part in this research for their understanding and combine effort.

\section{Authors' contributions}

OBO and OFF conceived the investigation, drafted the study procedure, designed the survey form, managed every section of this study, which include overseeing data collection in the communities, conducting data analysis and outlining the manuscript. AIA, funded research, drafted the study procedure, writing discussion and editing of the final draft for publication. BOA editing of the final draft for publication, DMA drafted the study procedure, discussion and editing of the final draft for publication.

\section{Conflict of Interest}

The authors declare that there is no conflict of interests regarding the publication of this paper.

\section{Reference}

Agudo, A., (2004). Measuring intake of fruit and vegetables. Background paper for the Joint FAO/WHO Workshop on Fruit and Vegetables for Health. WHO Library Cataloguing in Publication Data

Bhuiyan, A. R., Gustat, J., Srinivasan, S. R., \& Berenson, G. S. (2003). Differences in body shape 
representations among young adults from a biracial (Black-White), semirural community: The Bogalusa Heart Study. American Journal of Epidemiology, 158(8), 792-797. https://doi.org/10.1093/aje/kwg218

Boutelle, K., Neumark-Sztainer, D., Story, M., \& Resnick, M.,(2002). Weight control behaviours among obese, overweight, and overweight adolescents. Journal of Pediatric Psychology, 27(6), 531-540. https://doi.org/10.1093/jpepsy/27.6.531

Brener, N., Eaton, D., \& Lowry, R. (2004). The association between weight perception and BMI among high school students. Obesity Research \& Clinical Practice Journal, 12, 1866-1874. https://doi.org/10.1038/oby.2004.232

Burns, C. M., \& Tijhuis, M. A. (2001). The relationship between quality of life and perceived body weight and dieting history in Dutch men and women. International journal of obesity and related metabolic disorders, 25, 1386-1392. https://doi.org/10.1038/sj.ijo.0801714

Darshini, D., \& Rajesh, J. (2013). Body Weight Perception and Weight Control Practices Among Teenagers. International Scholarly Research Notices Nutrition Journal, 6. https://doi.org/10.5402/2013/395125

Dorosty, A. R., Mehdikhani, S., Sotoudeh, G., Rahimi, A., Koohdani, F., \& Tehrani, P. (2014). Perception of Weight and Health Status among Women Working at Health Centres of Tehran. Journal of Health, Population and Nutrition, 32(1), 58-67.

Elizabeth, L., Kiang, L., Gina, S. W., Bonnie, S., Catarina, K., \& Philip, G. (2009). The Relation Between Body Size Perception and Change in Body Mass Index Over 13 Years The Coronary Artery Risk Development in Young Adults (CARDIA) Study. American Journal of Epidemiology, 169, 857-866. https://doi.org/10.1093/aje/kwn412

Ettarh, R., Van de Vijver, S., Oti, S., \& Kyobutungi, C. (2013). Overweight, Obesity, and Perception of Body Image Among Slum Residents in Nairobi, Kenya, 2008-2009. Preventing Chronic Disease Journal, 10, 130198. https://doi.org/10.5888/10.130198.

Goodman, E., \& Hinden, B.(2000). Accuracy of teen and parental reports of obesity and body mass index. Journal of Pediatrics, 106, 52-58. https://doi.org/10.1542/peds.106.1.52

Iliyasu, Z., Abubakar, I., Abubakar, S., Lawan, U., \& Gajida, A. (2013). A survey of weight perception and social desirability of obesity among adults in Kano metropolis, Northern Nigeria. Nigerian Journal of Medicine, $22,101-108$

Knight, T., \& Illingworth, K. (2009). Health implications of body size perception and weight tolerance in older adults. Journal of Health Psychology, 14, 425-434. https://doi.org/10.1177/1359105309102198

Mahshid, D., Noori, A., \& Anwar, T. (2005). Childhood obesity, prevalence and prevention. Nutrition Journal, 4, 24. https://doi.org/10.1186/1475-2891-4-24

Manyanga, T., El-Sayed, H., \& Doku, D. (2014). The prevalence of underweight, overweight, obesity and associated risk factors among school-going adolescents in seven African countries. BMC Public Health, 14(887). https://doi.org/10.1186/1471-2458-14-887

Marie, N. G., Fleming, T., Robinson, M., Thomson, B., Graetz, N., Margono, C., ... Walid, A. (2013). Global, regional, and national prevalence of overweight and obesity in children and adults during 1980-2013: a systematic analysis for the Global Burden of Disease Study. Lancet, 10, 384. http://www.ncbi.nlm.nih.gov/pubmed/24880830

Maruf, F. A., \& Akinpelu, A. O. (2014). Differential perceptions of body image and body weight among adults of different socioeconomic status in a sub-urban population. Journal Biosocial Science, 46, 279-293. https://doi.org/10.1017/S002193201300028X

Maruf, F. A., Akinpelu, A. O., \& Nwankwo, M. J. (2012). Perceived body image and weight: discrepancies and gender differences among University undergraduates. African Health Sciences, 12(4), 464-472

Okeke, E. C., \& Ibeh, G. N. (2006). Body weight perception among Igbo people in the University of Nigeria, Nsukka. Journal of Tropical Agriculture, Food, Environment and Extension, 5, 17-24.

Olaoye, O., \& Oyetunde, O. (2012). Perception of weight and weight management practices among students of a tertiary institution in south-west Nigeria., Journal of Applied Pharmaceutical Science, 2(1), 81-84.

Onis, M., Onyango, A., Borghi, E., Siyam, A., \& Nishida, C.(2007). Development of a WHO growth reference for school-aged children and adolescents. Bulletin of World Health Organization, 85(9), 660-667. 
https://doi.org/10.2471/BLT.07.043497

Population and Housing Census of the Federal Republic of Nigeria. (2006). Population and housing census priority tables, Nigeria: National Population Commission.

Strauss, R. S. (2000). Childhood obesity and self-esteem. Journal of the American Academy of Pediatrics, 105(1), e15. https://doi.org/10.1542/105.1.15

Torres-McGehee, T. M. (2012). Eating Disorder Risk and the Role of Clothing in Collegiate Cheerleaders' Body Images. Journal of Athletic Training, 47(5), 541-548. https://doi.org/10.4085/1062-6050-47.5.03

Trishnee, B., \& Rajesh, J. (2014). Overweight and Obesity Epidemic in Developing Countries: A Problem with Diet, Physical Activity, or Socioeconomic Status? Scientific World Journal, 2014(2014), 7. http://doi.org/10.1155/2014/964236

Wong, M. (2010). Body weight perception and methods of weight reduction used by patients with first-episode psychotic disorders in Hong Kong. East Asian Archives Psychiatry, 20(4), 169-173

World Health Organization Multicentre Growth Reference Study Group.(2006). W.H.O child growth standards based on length/height, weight and age. Acta Paediatrica, 450, 76-85.

Yan, A, F., Harris, B. M., \& Wang, M. O. (2009). Weight Perception and Weight Control Practice in a Multiethnic Sample of US Adolescents. Southern Medical Journal, 102(4), 354-356.

https://doi.org/10.1097/SMJ.0b013e318198720b

\section{Appendix 1}

Sociodemographic characteristics of respondents

Table 4. Socio-Demographic Characteristics of Respondents

\begin{tabular}{|c|c|c|c|c|}
\hline & & Rural & & Urban \\
\hline Variables & Frequency(n) & Percentage $(\%)$ & Frequency(n) & Percentage $(\%)$ \\
\hline \multicolumn{5}{|l|}{ Sex } \\
\hline Male & 183 & 46.3 & 230 & 44.4 \\
\hline Female & 212 & 53.7 & 288 & 55.6 \\
\hline \multicolumn{5}{|l|}{ Age(years) } \\
\hline $10-14$ & 35 & 8.9 & 135 & 26.1 \\
\hline $15-19$ & 360 & 91.2 & 383 & 73.9 \\
\hline \multicolumn{5}{|l|}{ Religion } \\
\hline Christianity & 197 & 50.1 & 410 & 79.1 \\
\hline Islam & 188 & 47.8 & 105 & 20.3 \\
\hline Tradition & 7 & 1.8 & 1 & 0.2 \\
\hline Others & 1 & 0.3 & 2 & 0.4 \\
\hline \multicolumn{5}{|l|}{ Living with } \\
\hline Both parents & 295 & 74.8 & 433 & 84.6 \\
\hline Father alone & 33 & 8.4 & 17 & 3.3 \\
\hline Mother alone & 56 & 14.2 & 46 & 8.9 \\
\hline Siblings & 5 & 1.3 & 7 & 1.4 \\
\hline Other relation & 5 & 1.3 & 9 & 1.8 \\
\hline \multicolumn{5}{|l|}{ Father education } \\
\hline No formal education & 17 & 4.4 & 2 & 0.4 \\
\hline Primary education & 41 & 10.6 & 8 & 1.6 \\
\hline Junior secondary & 46 & 11.9 & 15 & 2.9 \\
\hline Senior secondary & 150 & 38.9 & 97 & 18.9 \\
\hline Tertiary/university & 132 & 34.2 & 392 & 76.2 \\
\hline \multicolumn{5}{|l|}{ Mother education } \\
\hline No formal education & 12 & 3.2 & 2 & 0.4 \\
\hline Primary education & 36 & 9.6 & 12 & 2.4 \\
\hline Junior secondary & 36 & 9.6 & 12 & 2.4 \\
\hline Senior secondary & 178 & 47.5 & 110 & 21.6 \\
\hline Tertiary/university & 113 & 30.1 & 373 & 73.2 \\
\hline
\end{tabular}


Table 5. Demographic Characteristics of Respondents

\begin{tabular}{lllll}
\hline & \multicolumn{3}{l}{ Rural } & Urban \\
\hline Variables & Frequency(n) & Percentage (\%) & Frequency(n) & Percentage (\%) \\
\hline Father occupation & & & & \\
Professional & 72 & 19.3 & 216 & 43.9 \\
Artisan & 52 & 13.9 & 18 & 3.7 \\
Business owner & 134 & 35.9 & 128 & 26.0 \\
Civil servant & 19 & 5.1 & 73 & 14.9 \\
Clergy & 16 & 4.3 & 23 & 4.7 \\
Military & 22 & 5.9 & 14 & 2.9 \\
Unemployed & 58 & 15.6 & 19 & 3.9 \\
Mother occupation & & & & \\
Professional & 44 & 11.9 & 175 & 35.4 \\
Artisan & 32 & 8.7 & 23 & 4.7 \\
Business owner & 264 & 71.7 & 219 & 44.2 \\
Civil servant & 6 & 1.6 & 60 & 12.1 \\
Clergy & 3 & 0.8 & 6 & 1.2 \\
Unemployed & 19 & 5.3 & 12 & 2.4 \\
\hline
\end{tabular}

\section{Appendix 2}

STUNKARD FIGURE RATING SCALE SILHOUETTE
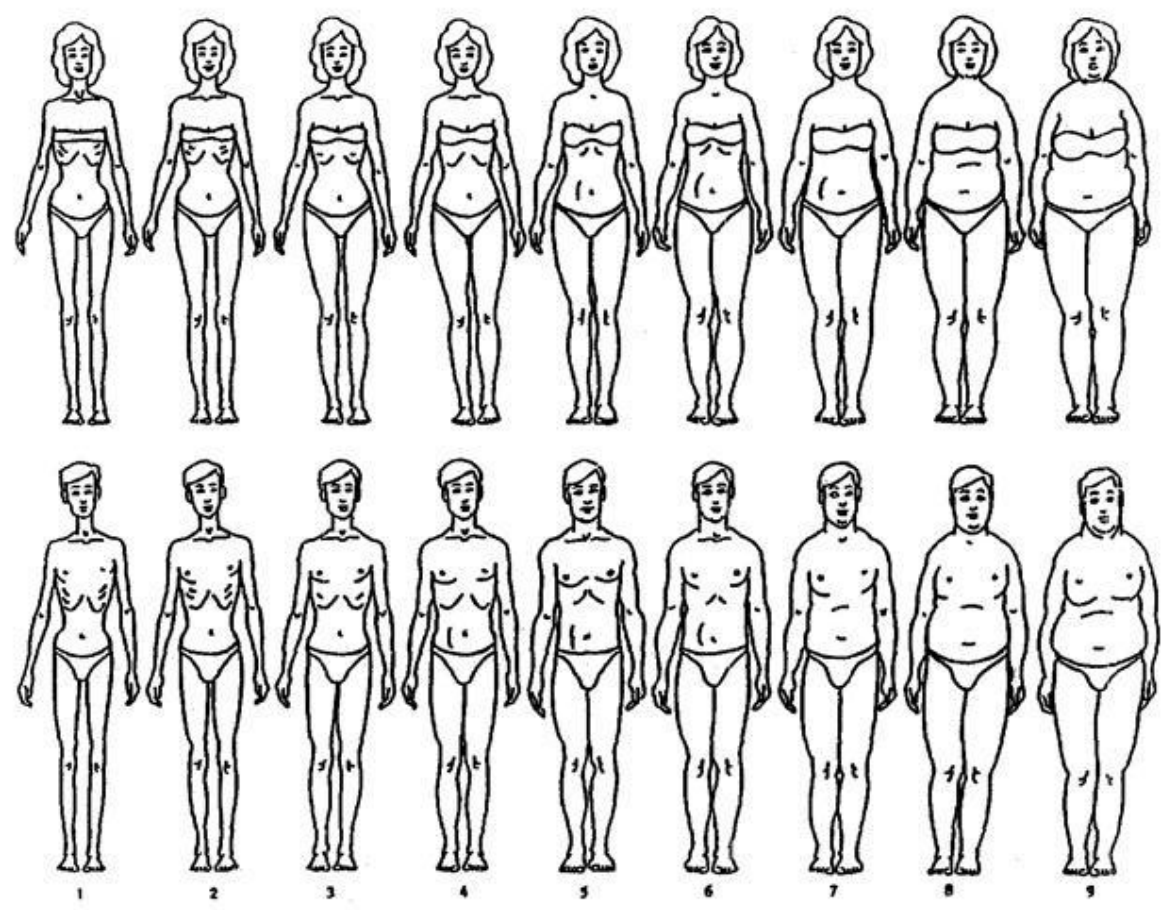

Figure 2. Stunkard Figure Rating Scale Silhouette (Elizabeth et al., 2009)

- Figure 1 - Figure 2= "Underweight

- Figure 3 - Figure 4 = "Normal Weight"

- Figure 5- Figure 6 = "Overweight"

- Figure 7- Figure 8 = "Obese"

\section{Copyrights}

Copyright for this article is retained by the author(s), with first publication rights granted to the journal.

This is an open-access article distributed under the terms and conditions of the Creative Commons Attribution license (http://creativecommons.org/licenses/by/4.0/). 